\title{
Experimental and Modeling Dynamic Study of the Indirect Solar Water Heater: Application to Rabat Morocco
}

\author{
Ouhammou Badr ${ }^{1}$, Azeddine Frimane ${ }^{2}$, Aggour Mohammed $^{3}$, Brahim Daouchi $^{4}$, Abdellah Bah $^{5}$, \\ Halima Kazdaba ${ }^{6}$ \\ 1,2,3,4 Renewable Energy and Environment Laboratory, Department of Physics, Faculty of Sciences Ibn Tofail University, \\ B.P 133, 14 000, Kenitra, Morocco \\ ${ }^{5,6}$ Equipe de Recherche Thermique, Energie et Environnement (ERTEE), Laboratoire LM2PI ENSET, Universite \\ Mohammed V, Rabat, Marocco
}

\section{Article Info \\ Article history: \\ Received Jun 17, 2017 \\ Revised Jan 20, 2018 \\ Accepted Feb 11, 2018}

\section{Keywords:}

Dynamic multi-node model Forced circulation Solar collector application Thermal performance Water heater

\begin{abstract}
The Indirect Solar Water Heater System (SWHS) with Forced Circulation is modeled by proposing a theoretical dynamic multi-node model. The SWHS, which works with a 1,91 m2 PFC and $300 \mathrm{~L}$ storage tank, and it is equipped with available forced circulation scale system fitted with an automated subsystem that controlled hot water, is what the experimental setup consisted of. The system, which $100 \%$ heated water by only using solar energy. The experimental weather conditions are measured every one minute. The experiments validation steps were performed for two periods, the first one concern the cloudy days in December, the second for the sunny days in May; the average deviations between the predicted and the experimental values is $2 \%, 5 \%$ for the water temperature output and for the useful energy are $4 \%, 9 \%$ respectively for the both typical days, which is very satisfied. The thermal efficiency was determined experimentally and theoretically and shown to agree well with the EN12975 standard for the flow rate between $0,02 \mathrm{~kg} / \mathrm{s}$ and $0,2 \mathrm{~kg} / \mathrm{s}$.
\end{abstract}

Copyright (C) 2018 Institute of Advanced Engineering and Science. All rights reserved.

\section{Corresponding Author:}

Ouhammou Badr,

Renewable Energy and Environment Laboratory, Department of Physics,

Faculty of Sciences Ibn Tofail University, B.P 133, 14 000, Kenitra, Morocco.

Email: badr.ouhammou@uit.ac.ma

\section{INTRODUCTION}

The most common use of thermal solar energy has been for water heating systems; this use has been commercialized in many countries in the world. Solar heating systems have many innovations and developments in the last years. Their applications have increased significantly, especially in countries with large solar potential such as our case Morocco.

Thermal solar collector systems (water heating) can be used in two ways, by forced circulation systems or systems with natural circulation [1]. The modern research in thermal engineering is a combination of numerical and experimental aspects. In addition, many models and studies were carried out; for example, Duffie and Beckman [2] developed a model of design and prediction for the flat plate solar collector. In addition, Close et al [3], have developed a model named by 1n-node, also we have the model 2n-node and 3n-node developed by [4] and [5] respectively, in the same direction the works of Isakson et al [6], De Ron et al[7], Huang et al [8], Schnieders et al [9], Fraisse et al [10], Cadaflach et al [11], and Molero Villar et al [12] have participated effectively in the development and modeling of this system. Furthermore, many norms describe the test procedures for the performances of thermal solar collectors have been generated. The best known are the ISO-9806-1 [13], the ASHRAE standard 93 [14] and EN12975 [15].

The simulation using the current model was shown to agree well with the experiment results. The objective of this work is to validate the theoretical model by performing a number of simple experiences for different weather conditions in purpose to evaluate the thermal performance of the SWH also, thinking of 
using new alternatives for numerical simulation and use it after for another application as coupled it with others software (TRNSYS) in order to use the model in the building heating.

\section{MODELING OF THE SYSTEM}

\subsection{The Heat Transfer Coefficients} coefficients.

Before forming the model, we exposed the most used models in the estimation of the heat transfer

The transfer coefficient by convection between glass cover and ambient is calculated by the empirical relationship of Adams and Woertz [19]:

$$
h_{c v, \text { out }}=5,67+3,86 V_{w}
$$

The radiation coefficient between the glass cover and the sky is given by (Soteris Kalogirou 2014):

$$
h_{r, g-s k y}=\varepsilon_{v} \sigma\left(T_{g}+T_{s k y}\right)\left(T_{g}^{2}+T_{s k y}^{2}\right)
$$

Where the temperature of the sky is correlated by the following formula (Soteris Kalogirou 2014):

$$
T_{\text {sky }}=0,0552 T_{a m}^{1,5}
$$

The radiation coefficient between two infinite parallel surfaces, (i) and (j) [1]:

$$
h_{r}=\frac{\sigma\left(T_{i}-T_{j}\right)\left(T_{i}^{2}-T_{j}^{2}\right)}{\frac{1-\varepsilon_{i}}{\varepsilon_{i}}+\frac{1-\varepsilon_{j}}{\varepsilon_{j}}-1}
$$

The coefficient of conduction is given by the following equations:

$$
h_{c d}=\sum \frac{e_{i}}{K_{i}}
$$

For the coefficient of convection between cover and absorber is calculated by the following empirical formula given by [1].

$$
\begin{aligned}
& h_{c v, p-g}=\frac{N u K_{a i r}}{D} \\
& N u=1+1,446\left[1-\frac{1708}{R a \cos (\beta)}\right]^{+}\left\{1-\frac{1708[\sin (1,8 \beta)]^{1,6}}{R a \cos (\beta)}\right\}+\left\{\left[\frac{R a \cos (\beta)}{5830}\right]^{0,333}-1\right\}
\end{aligned}
$$

The Rayleigh value ( $\mathrm{Ra})$ is given by:

$$
R a=\frac{g \beta^{\prime} \operatorname{Pr}}{v^{2}}\left(T_{p}-T_{g}\right) l^{3}
$$

The forced convection coefficient absorber-fluid $h_{c v, f-p}$ is calculated according to the empirical formulas (equations 15, 16 and 17) given by the works of Haussen and Sider-Tate [19]. For $\operatorname{Re}<2100$ :

$$
\mathrm{Gz}<100 \quad N u=3,66+\frac{0,085 G z}{1+0,047 G^{\frac{2}{3}}}
$$




$$
\mathrm{Gz}>100 \quad \mathrm{Nu}=1,86 G \mathrm{z}^{\frac{1}{3}}+0,87\left(1+0,015 G z^{\frac{1}{3}}\right)
$$

For $2100<\operatorname{Re}<10000$ :

$$
N u=0,116\left(\operatorname{Re}^{\frac{2}{3}}-125\right) \operatorname{Pr}^{\frac{1}{3}}\left(1+\frac{D}{N L}\right)^{\frac{2}{3}}
$$

\subsection{The Heat Transfer Coefficients}

As the other models, the present one is based on mass and energy conservation laws. The solar water heater is formed by many elements as shown in table.2 and in Figure.1.

Before starting, the following assumptions are made to simplify the analysis:

a. The physical properties and thermal fluid data are based on the average temperature.

b. Irradiation is uniform for all area of the collector.

c. The ambient temperature is the same around the collector.

d. The thermal exchange by convection between the insulation and ambient is negligible.

e. Properties of materials are independent of temperature.

Thus it is necessary to define step by step the singular heat flow equations in order to find the governing equations of the collector system.

\subsubsection{Heat Balance Of The Glass Cover}

The energy comes from the sun in the form of radiation and penetrates the aperture plane of the solar collector. However, a part of this radiation is reflected back to the sky, another component is absorbed by the glazing and the rest is transmitted through the glazing and reaches the absorber plate as short wave radiation. The equation 12 expressed the heat balance in this element.

$(m C p)_{g} \frac{d T_{g}}{d t}=S\left[\left(\alpha_{g} G\right)+h_{r, g-s k y}\left(T_{s k y}-T_{g}\right)+\left(h_{r, g-\text { ground }}+h_{c v, \text { out }}\right)\left(T_{a m}-T_{g}\right)-\left(h_{r, g-a b s}+h_{c v, g-p}\right)\left(T_{p}-T_{g}\right)\right]$

\subsubsection{Heat Balance of the Absorber}

The absorber receives energy coming from the sun through glass cover by radiation exchange with glass and at the same time transferred this energy into the fluid. Knowing that a part of energy transferred is lost because of the heat exchange with cover and with insulation by convection and conduction respectively as shown in the equation 13.

$$
(m C p)_{p} \frac{d T_{p}}{d t}=S\left[\left(\alpha_{p} \tau_{g} \alpha_{g} G\right)-\left(h_{r, g-p}+h_{c v, g-p}\right)\left(T_{p}-T_{g}\right)+h_{c v, p-f}\left(T_{f m}-T_{p}\right)-h_{c d, p-i n s}\left(T_{i n s}-T_{p}\right)\right]
$$

\subsubsection{Heat Balance of the Fluid}

In this model, the exchanges existed only by forced convection between absorber and the water (working fluid) as it's shown in the following equation:

$$
(\rho \vee C p)_{f} \frac{d T_{f}}{d t}=h_{c v, p-f} \mathrm{~S}\left(T_{p}-T_{f}\right)
$$

\subsubsection{Heat Balance of the Insulation}

The heat exchange concerning this element is those between the absorber and insulation by conduction ( $h_{c d, a b s-i n s}$ ), also between insulation and ambient by radiation ( $h_{r, \text { ins-ground }}$ ) as illustrate in the following equation:

$$
(m C p)_{i n s} \frac{d T_{\text {ins }}}{d t}=S\left[h_{c d, a b s-i n s}\left(T_{\text {ins }}-T_{p}\right)+\left(h_{r, \text { ins-ground }}\right)\left(T_{a m}-T_{\text {ins }}\right)\right]
$$




\subsection{Performances of Solar Collector}

The thermal performance of solar collectors can be determined by the details analysis of the optical and thermal characteristics of the collector materials and collector design (theoretical modeling) or by experimental performance tested under different weather conditions (experimental validation). Solar collectors can be tested by two basic methods: under steady-state conditions or using a dynamic test procedure which adopted this work.

The collector efficiency is given by the following equation:

$$
\eta=\frac{Q_{u}}{Q_{0}}=\frac{m C_{p}\left(T_{f}-T_{i}\right)}{G S}
$$

Also, and according to EN12975 [15] for FPCs, the efficiency curve can be written as:

$$
\eta=\eta_{0}-a_{1} \frac{(\Delta T)}{G}-a_{2} \frac{(\Delta T)^{2}}{G}
$$

where:

$\eta_{0}$ : Optic efficiency

$a_{1}$ and $a_{2}$ : are the coefficient of the losses according to EN12975 standard.

$G$ : Global solar radiation $\left(\mathrm{Wm}^{-2}\right)$.

$\Delta T$ : The temperature difference $(\mathrm{K})$.

\section{METHODS AND MATERIALS}

\subsection{Global Algorithm}

Because of the complexity structure and multiplicity of equations of our model, the method of Runge-Kutta $4^{\text {th }}$ order [20] was adopted for solving numerically the following systeme of equation:

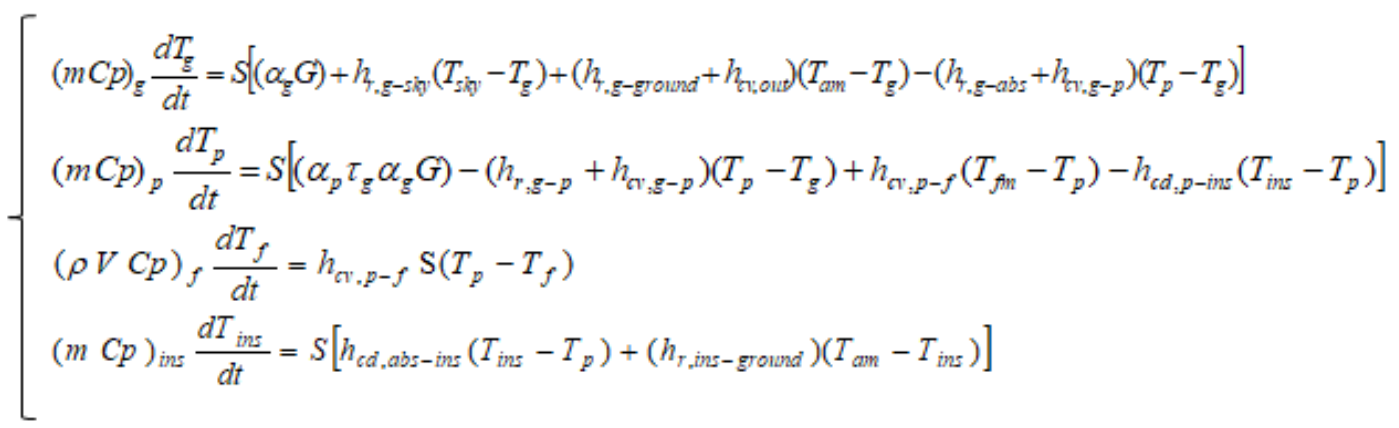

The Figure 1 shows the global algorithm following to run and solve numericaly the systeme (18).

a. Block I: Calculation of the solar radiation

In this step, we adapted the model of Perrin de Brichambaut $[16,17]$ as mentioned previously. In the beginning we input the parameters of Longitude, latitude, day number and number of the month for calculating declination angle and hour angle, and consequently the incidence angle (i) and the high of sun (h) are calculated, after this step we input the coefficients exposed in table.2, in the end of this part we have been calculated the global solar radiation.

b. Block II: Calculation of The thermal performance

Inputting the physics properties (Specific heat at constant pressure, wind speed, thermal conductivity and volume density) of water, the geometric parameters exposed of the system. After this step of this program starts to calculate the all type heat coefficients $\left(\mathrm{h}_{\mathrm{r}}, \mathrm{h}_{\mathrm{cv}}, \mathrm{h}_{\mathrm{cd}}\right)$ by adapting the formulas exposed previously.

In the end of this step we have adapted the numerical method in order to resolve the system of differential equations and consequently the thermal performances $\left(\eta ; Q_{u}\right)$ are calculated. 


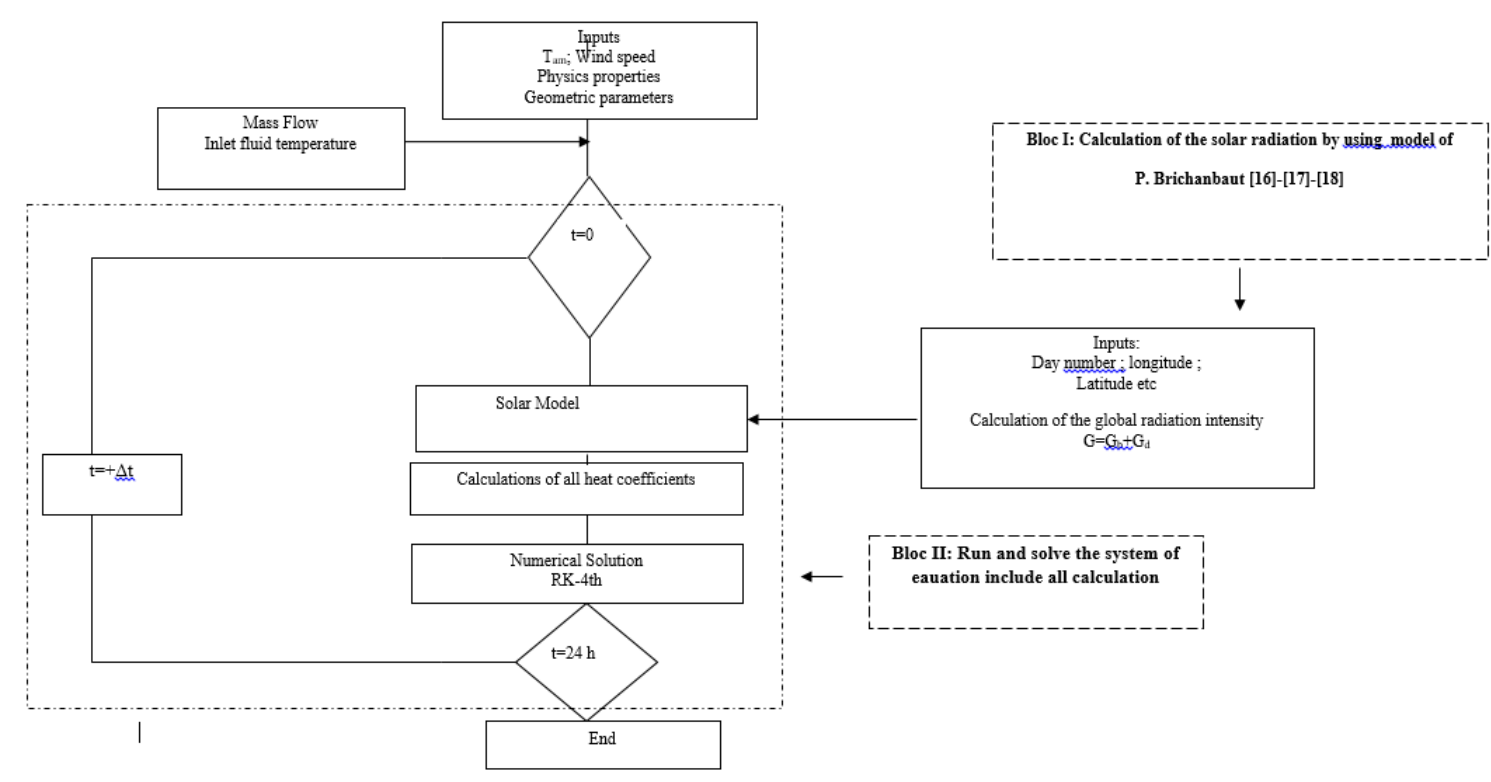

Figure 1. Global algorithm of solving the systemof equation

\subsection{Experimental Set-up}

The experimental apparatus is located on the terrace roof of the Laboratory of Energy of the Higher School of Technical Education, Rabat (Latitude: $34^{\circ} 0$ 0 47" N; Longitude: $6^{\circ} 49^{\prime} 57 "$ 0; Altitude 46 m). Indirect SWH system with forced circulation consists of $2 \mathrm{~m}^{2} \mathrm{FPC}$, a 300L hot water tank heated only by solar energy and with an automated sub-system that controlled hot water. In this experiment, the tank heats continuously in three days in May and December, without emptied the tank. We preferred to collect data every fifteen minutes during the day from Sunrise to sunset.

Solar water heating system consists of a hot water storage tank (Figure.2.b), control unit, pump station (Figure.2.c), and flat plate collector (Figure.2.a). The FPC employed in this study was south facing and inclined at $40^{\circ}$. The hot water tank was installed inside the laboratory while the FPC was set up in the building plant room. The solar circuits consisted of two types of pipes. The first one is a $4.7 \mathrm{~m}$ of copper pipe type which is of $18 \mathrm{~mm}$ diameter (inside) and $22 \mathrm{~mm}$ diameter (outside) that comes from the tank followed by a $26 \mathrm{~m}$ of caoutchouc pipe type to FPC with $19 \mathrm{~mm}$ diameter (inside) and $23 \mathrm{~mm}$ diameter (outside). In order to minimize the losses of heat, we opted for using Armaflex with $26 \mathrm{~mm}$ of diameter (outside) set up as insulation for all pipe fittings. The solar circuit pipe length supply and return were $4 \mathrm{~m}$ of copper and $25 \mathrm{~m}$ of caoutchouc. The collecting system consisted of Dietrisol ECO 2.1 flat plate collector with a gross area of $2.06 \mathrm{~m}^{2}$ and aperture area of $1,91 \mathrm{~m}^{2}$. The solar collector constitutes a box which ensures an effective longterm protection, consisting of a framework, an aluminum bottom and successively equipped with the single transparent cover glass of $3.2 \mathrm{~mm}$ of thickness and an air gap which was located between the cover and the absorber which has a $1.2 \mathrm{~cm}$ of thickness. The absorber has a geometry constitutes copper pipes welded with an aluminum foil where the fluid can be circulated by means of the solar circulator, and an insulator (mineral Wool) a $40 \mathrm{~mm}$ thickness, the sizes of the FPC is illustrated in table 1.

Table 1. Specifications of the Different Components of the Solar Collector Used in the Present Study

\begin{tabular}{|c|c|c|c|c|}
\hline \multirow[t]{2}{*}{ Gross dimensions : } & Width (m) & 1,147 & Depth (m) & 0,087 \\
\hline & Length (m) & 1,753 & & \\
\hline Transparent cover : & Length (m) & 1,134 & Mass (kg) & 16,4 \\
\hline Material & Height (m) & 1,740 & & \\
\hline \multirow{2}{*}{ Soda lime silicate glass } & Thickness (m) & 0,0032 & & \\
\hline & Air gap (m) & 0,012 & $\begin{array}{l}\text { Mass air gap } \\
(\mathrm{kg})\end{array}$ & 0,027 \\
\hline Absorber : & Length ( $\mathrm{m}$ ) & 1,100 & & \\
\hline Material & Height (m) & 1,706 & Mass (kg) & 10,026 \\
\hline Aluminum plate Coating: copper & Thickness (m) & 0,004 & & \\
\hline Insulation : & Thickness (m) & 0,040 & & \\
\hline Material & With (m) & 1,717 & Mass (kg) & 3,056 \\
\hline Mineral wool & Height (m) & 1,1145 & & \\
\hline
\end{tabular}


The working fluids used in solar collectors are mixtures of $30 \%$ glycol/water. The collector had maximum operating and stagnation temperatures of $164^{\circ} \mathrm{C}$ and $213^{\circ} \mathrm{C}$ respectively, a maximum operating pressure of 10 bars. The stainless steel hot water tank (model BSC 300) was $1767 \mathrm{~mm}$ high with a diameter of $601 \mathrm{~mm}$ and an operating pressure of 10 bars. The tank had a heating coil with a surface area of $1.2 \mathrm{~m} 2 \mathrm{a}$ fluid content of $8,9 \mathrm{~L}$ and a rating of 21 . An automated hot water dispensing unit was designed and incorporated into the SWHS. The unit includes a programmable logic controller (PLC), contactors, relays, electrical fittings, and impulse flow meters. PLC was used to control circulation of the Solar fluid between the tank and the PFC, that is when the difference in temperature between the hot water in the bottom of the tank and the PFC is superior to $5^{\circ} \mathrm{C}$ the PLC allows the circulation, while when it is inferior to $3^{\circ} \mathrm{C}$ the PLC stops the circulation. A pulse flow meter (1 pulse per liter) was used to count the number of liters of Solar Fluid from the PFC.

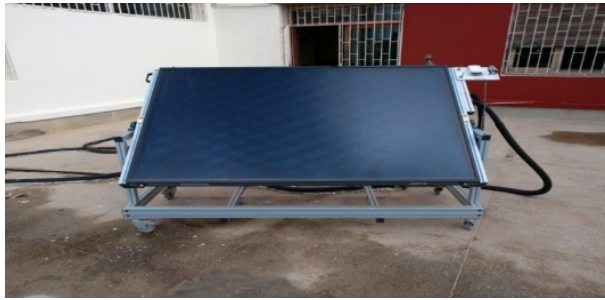

a)

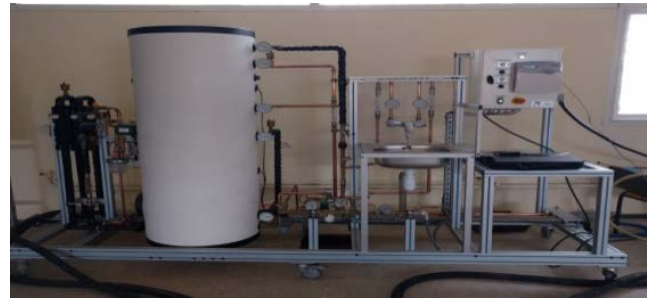

b)

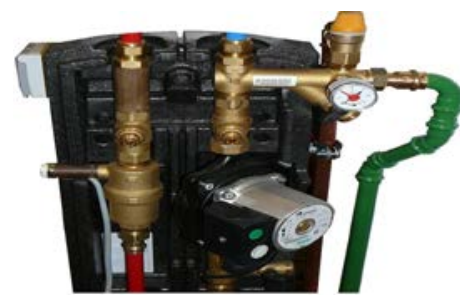

C)

Figure 2. The test bench, (a) solar collector, (b) storage tank and (c) pump type ST 15/6 ECO, used in the experimental measurement

The SWH is equipped with a RESOL DeltaSol (Figure.3.a) M solar controller which has relay inputs to control the operation of the solar pump station. It also has temperature sensor inputs onto which PTIOOO platinum resistance temperature sensors are connected to measure water and solar fluid temperatures (Figure 1). The volumetric flow rate of the solar fluid is measured using RESOL V 40-06 impulse flow meters which react at $1 \mathrm{l}$ per pulse. RESOL DL2 data loggers are used to store data every fifteen minutes from the RESOL DeltaSol M solar controllers via RESOL VBus cables. DL2 data loggers are equipped with a secure digital (SD) drive and a local area network (LAN) port for direct connection to a personal computer (PC). Data from the loggers are extracted using a Web browser or an SD card. Global solar radiation on the collector's surface is measured using CSI0 Solar cell type E (Figure 3.b).

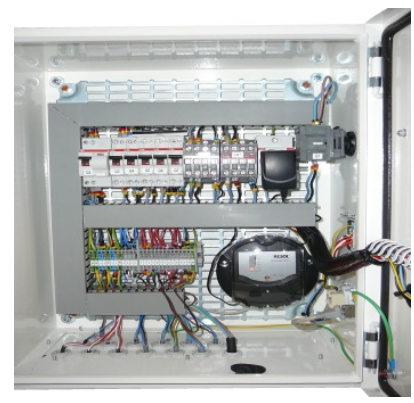

(a)

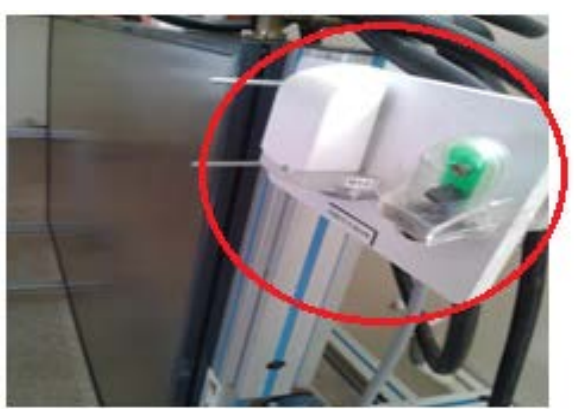

(b)

Figure 3. the RESOL data acquisition system (a) and cell Type RESOL CS10 (b) 


\section{RESULTS AND ANALYSIS}

The main objective of the experimental test is to valid the theory model. In this paragraph, many capabilities of our model will be exposed for a sunny and cloudy days. The characteristics of the site and the parameters used in the simulation are given in Table 2. The curves exposed in Figure.4 shows the shape of the instantaneous efficiency obtained by the theoretical model, the simple experiments and also by the EN12975 standard.

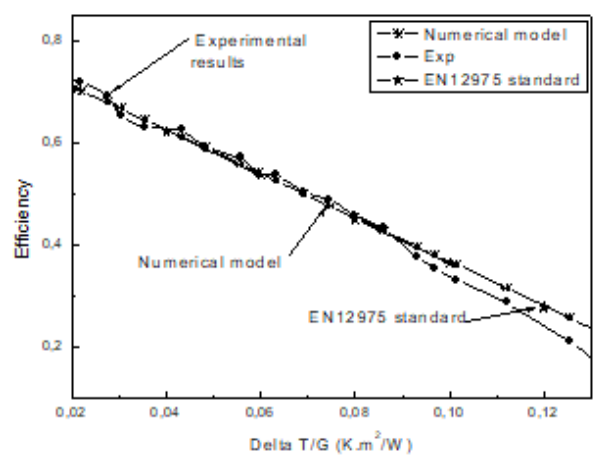

Figure 4. Collector efficiency versus $\Delta \mathrm{T} / \mathrm{G}$.

The difference between the experimental and the theoretical results is $1,2 \%$ and the same thing between the theoretical curve and this one obtained by EN12975 standard. It's noted that the fluid outgoing of the tank and entered the collector has a temperature equal to the first temperature in the beginning; i.e. we always keep the same difference temperatures between the output and input. The difference between both curves (experimental and the theoretical) is observed in the high values of $\Delta \mathrm{T} / \mathrm{G}$, this means that the present system (SWH) may work in high temperature.

By using the quadratic function, the parameters of efficiencies curves illustrate in equation 23 are exposed in Table 2 in comparison with those given by constructor.

Table 2. Experiments and Simulation results of parameters efficiencies according to EN12975 standard

\begin{tabular}{llll}
\hline Parameters & Experiment & Simulation & $\begin{array}{l}\text { the constructor of } \\
\text { collector }\end{array}$ \\
\hline$\eta_{0}$ & 0,774 & 0,779 & 0,794 \\
$\mathrm{a}_{1}$ & 4,1 & 3,94 & 4,31 \\
$\mathrm{a}_{2}$ & 0,089 & 0,09 & 0,0120 \\
\hline
\end{tabular}

On the other side, the variation of the outlet fluid temperature during a typical sunny day is presented in Figure.5; as it's shown in the Figureure, the outlet temperature increases at the beginning, passed by a maximum and decreases towards the end of the day.

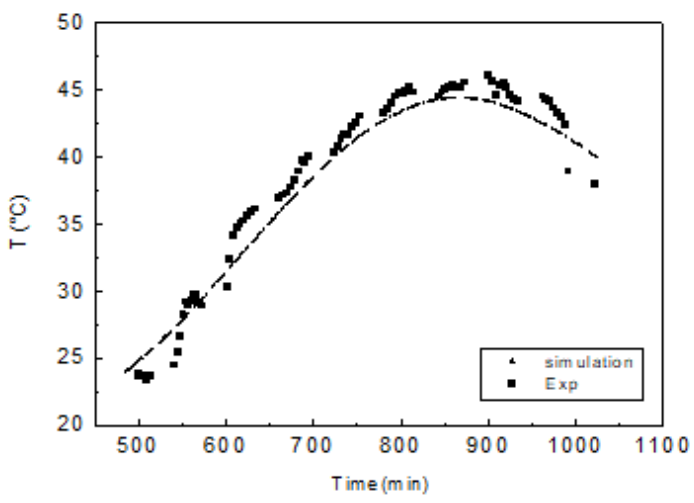

Figure 5. Variation of the outlet temperature of the working fluid for a typical sunny day 
This is due to the evolution of solar intensity flow during the day. The temperature of the fluid achieves in maximum about $44.4^{\circ} \mathrm{C}$ by simulation and $47^{\circ} \mathrm{C}$ experimentally. On the other hand, the fluctuations in the temperature of the absorber, as it is illustrated in Figure.6, they are caused by the changes of the ambient temperatures, glass cover transparent which is caused by the cloudy passages. The percentage error concerning the temperature of the absorber is $4 \%$ between the simulation and experimental results.

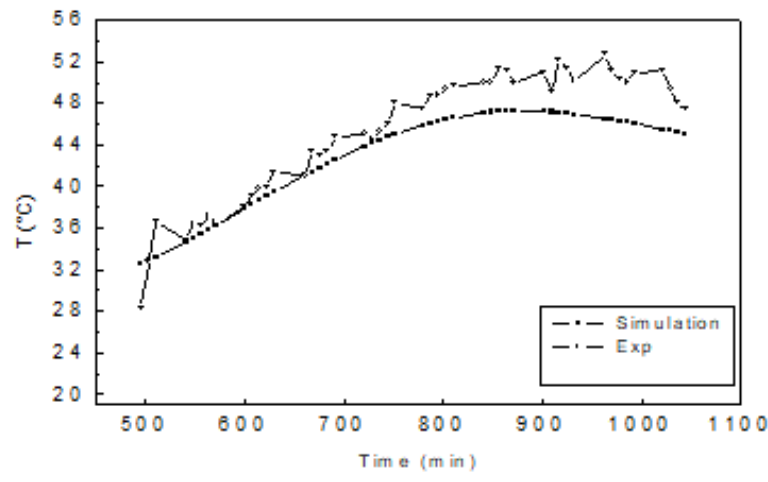

Figure 6. The variation of the temperature of the absorber of a typical sunny day.

On the other side, the Figure 7 shows the difference between changes of the useful energy extracted from the system. Not only simulation results tend to those of the experiments, but the value of the useful energy gain was almost closely predicted by the theoretical model

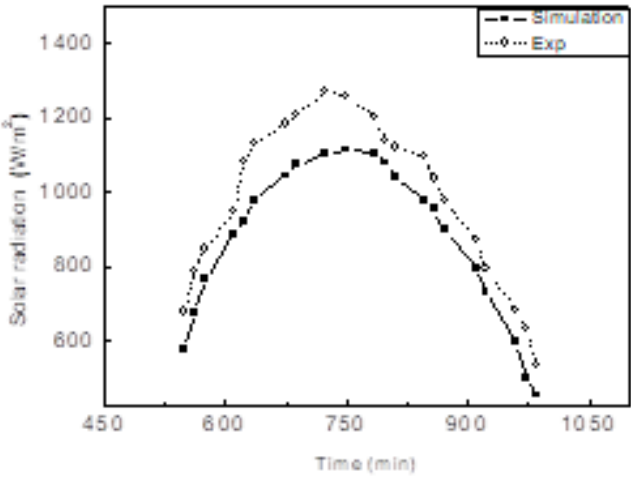

(a)

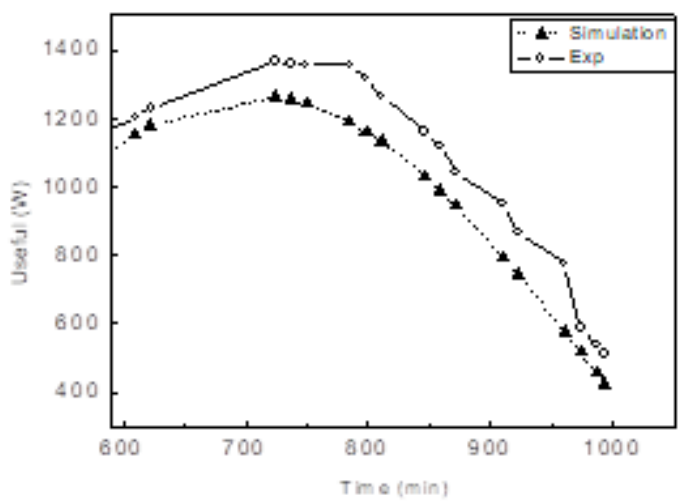

(b)

Figure 7. (a) Solar radiations and (b) Useful energy for a typical sunny day

As it's shown in Figure.7 the numerical model value is always under predicts value. Perhaps, among the reasons, is that the theoretical model takes the ambient temperature and wind speed as constant parameters in the calculation (constant inputs) on the contrary the experiment that has the fluctuation in these parameters. The solar intensity obtained experimentally is higher than the one obtained by simulation; this is due to the higher value of the Albedo that caused by the existence of the walls and a lot of equipment surround our system.

The performance of FPCs for a cloudy day is shown in Figureures 8-10. The evident point is the fluctuation of the instantaneous useful energy gain (Figureure.8.b), that caused by the strong changes in solar radiations as shown in the Figureure.8.a. 


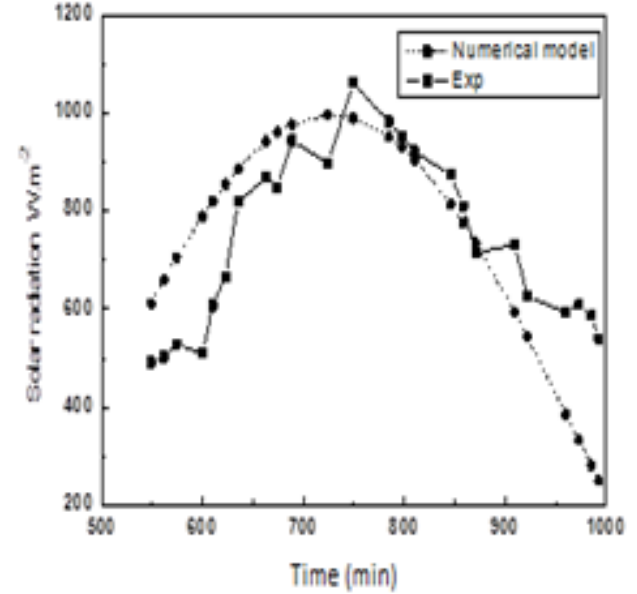

(a)

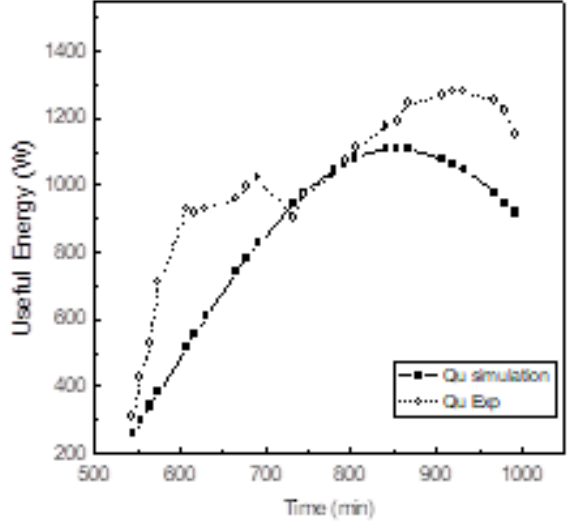

(b)

Figure 8. Solar radiations (a) and Useful energy (b) for a typical cloudy day

The retarded response is very clear in the afternoon. The useful energy and incident radiation (experimentally) has a maximum estimated about $1185 \mathrm{~W}$ and $1075 \mathrm{~W} / \mathrm{m}^{2}$ respectively. The numerical model is not well estimated of the useful energy gain extracted from the system for the typical cloudy day. Also, the outlet temperature has affected in the same way by the fluctuations of the solar intensity as shown in Figure.9.

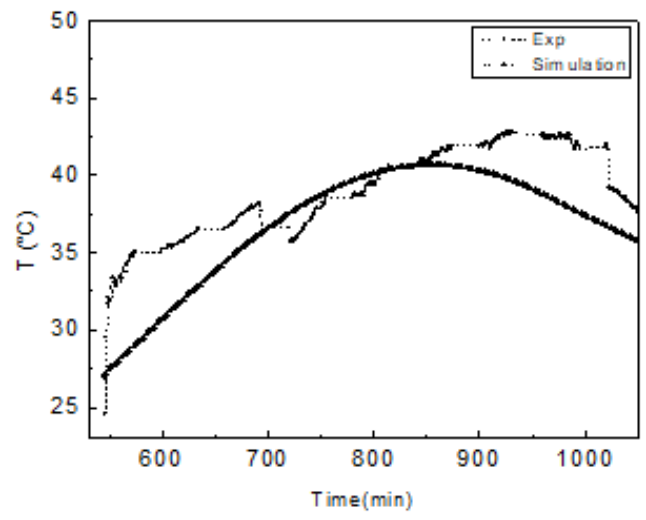

Figure 9. Variation of the outlet temperature of the working fluid for a typical cloudy day.

Nevertheless, the outlet fluid temperature of the collector was estimated with small discrepancies by simulation, i.e., the maximum experimental value is $42,8^{\circ} \mathrm{C}$ when the simulation is $40^{\circ} \mathrm{C}$. It's necessary to note that, when the solar radiations are quickly and unexpectedly increase or decrease, the fluid temperature doesn't change immediately, and according to the changes unexpected of solar radiations, the experimental efficiency curve is very different from the simulation as illustrated in Figure.10. 


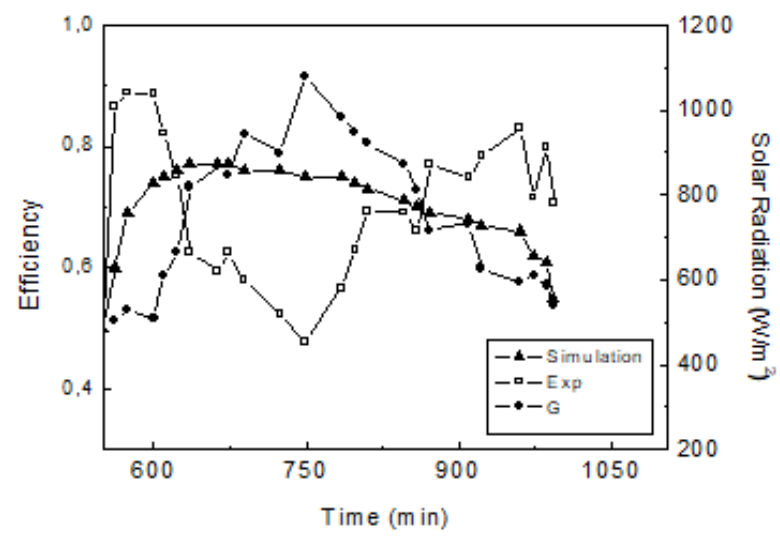

Figure 10. The transient efficiency of the collector for a typical cloudy day

When the solar radiation is not important, the measurements efficiency is higher than that obtained by simulation, the reason responsible for this increases value is because the difference between the inlet and outlet experimental temperatures, but for the simulation, as previously mentioned, the parameters inputs are constants. In the middle of the day, when the solar intensity increase as shown in Figure.10, the efficiency curve drops completely in a different way from that solar radiation.

The reasons for those deviations between our model and experimental results as illustrate in previous Figureures are the following:

a. Weather conditions, which were unstable during the experiences.

b. The simulation uses all parameters as a constant input.

c. The fluctuation in the measurements.

d. The distance between collector and storage tank is far.

e. The effect of the thermal inertia, i.e. it's impossible to achieve initial temperatures very close to the modeled ones.

f. The thermal and optic losses during the experience represent $11 \%$ and $20--\%$ respectively, for example for the cloudy day, the incident energy is $16920 \mathrm{KJ}$, the losses are $1862 \mathrm{KJ}$ and $3384 \mathrm{KJ}$ respectively , for the sunny day the energy incident is $23400 \mathrm{KJ}$,the losses are $4680 \mathrm{KJ}$ and $2574 \mathrm{KJ}$.

The measuring equipment may not be as accurate as it should be or as indicated by their manufacturers, i.e. the measurements of the solar radiation are carried out with a relative error of $10 \%$ and 3 $\%$ for the other different temperatures sensor.

\section{CONCLUSION}

The objective of this study was to model an indirect solar water heater with forced circulation and validate the model through simple experimental. The simulation is used on this model was shown to agree well with the experimental results such as:

a. The percentage error of outlet water temperature is $2 \%$ for the sunny days and $5 \%$ for the cloudy days.

b. The percentage error of useful energy is $4 \%$ and $9 \%$ for the sunny and cloudy days respectively.

c. The thermal efficiency curve of FPCs follows the same shape of EN12975 standard, which the coefficients $a_{1}$ and $a_{2}$ are equal to those of FPCs (type SOL 200) and the percentage error between them is $1,2 \%$.

This means that the model developed in the current work can be represented the real system and can be used to estimate its dynamic behavior.

\section{REFERENCES}

[1] Kalogirou SA (2004) "Solar thermal collectors and applications" Progress in Energy and Combustion Science 30:231-295. doi: 10.1016/j.pecs.2004.02.001

[2] Duffie JA, Beckman WA, Worek WM (1994) “Solar engineering of thermal processes”, 2nd ed. Journal of Solar Energy Engineering 116:67. doi: 10.1115/1.2930068

[3] Close DJ (1967) “A design approach for solar processes” Solar Energy 11:112-122. doi: 10.1016/0038092x(67)90051-5 
[4] Wijeysundera NE (1978) “Comparison of transient heat transfer models for flat plate collectors” Solar Energy 21:517-521. doi: 10.1016/0038-092x(78)90077-4

[5] Kamminga W (1985) "The approximate temperatures within a flat-plate solar collector under transient conditions" International Journal of Heat and Mass Transfer 28:433-440. doi: 10.1016/0017-9310(85)90076-6

[6] Isakson P (1995) "Solar collector model for testing and simulation” Final Report for BFR Project No. 900280-1, Building Services Engineering. Royal Institute of Technology, Stockholm.

[7] de Ron AJ (1980) "Dynamic modelling and verification of a flat-plate solar collector” Solar Energy 24:117-128. doi: 10.1016/0038-092x(80)90386-2

[8] Huang BJ, Wang SB (1994) "Identification of solar collector dynamics using physical model-based approach" Journal of Dynamic Systems, Measurement, and Control 116:755. doi: 10.1115/1.2899275

[9] Schnieders J (1997) "Comparison of the energy yield predictions of stationary and dynamic solar collector models and the models' accuracy in the description of a vacuum tube collector" Solar Energy 61:179-190. doi: 10.1016/s0038-092x(97)00036-4

[10] Achard G, Plantier C, Fraisse G (2003) "Development and experimental validation of a detailed flat-plate solar collector mode" 5th French and European TRNSYS User Meeting. France

[11] Cadafalch J (2009) “A detailed numerical model for flat-plate solar thermal devices” Solar Energy 83:2157-2164. doi: 10.1016/j.solener.2009.08.013

[12] Villar NM, López JMC, Muñoz FD, et al. (2009) "Numerical 3-D heat flux simulations on flat plate solar collector" Solar Energy 83:1086-1092. doi: 10.1016/j.solener.2009.01.014

[13] copyright (1994) Test methods for solar collectors -- part 1: Thermal performance of glazed liquid heating collectors including pressure drop. http://www.iso.org/iso/catalogue_detail.htm?csnumber=17678. Accessed 7 Jan 2017

[14] Huang BJ, Hsieh SW (1990) "An automation of collector testing and modification of ANSI/ASHRAE 93-1986 standard” Journal of Solar Energy Engineering 112:257. doi: 10.1115/1.2929932

[15] Shaner WW, Duff WS (1979) "Solar thermal electric power systems: Comparison of line-focus collectors" Solar Energy 22:49-61. doi: 10.1016/0038-092x(79)90059-8

[16] Perrinde Brichambaut C, Vauge C (1982) Le Gisement solaire: Évaluation de la ressource énergétique

[17] [Merzouk NK, Merzouk M (2014) “Performances théoriques et expérimentales des capteurs solaires” Editions universitaires européennes

[18] Cooper PI (1969) “The absorption of radiation in solar stills” Solar Energy 12:333-346. doi: 10.1016/0038092x(69)90047-4

[19] UNESCO documents and publications. http://unesdoc.unesco.org/ulis/cgi-bin/ulis.pl?database=ged\&req=2\&look=all\&no=123413(accessed December 19, 2016). Accessed 7 Jan 2017

[20] Kumar A, Unny TE (1977) "Application of Runge-Kutta method for the solution of non-linear partial differential equations” Applied Mathematical Modelling 1:199-204. doi: 10.1016/0307-904x(77)90006-3 